مقارنة بيوميكانيكية بين الذراع الضاربة لمهارة الإرسال بوجه المضرب الأمامي والإرسال بوجه المضرب الخلفي في الاسكواش

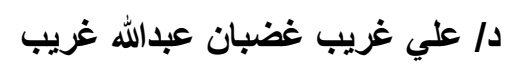

وزاره التربيه والتعليم ـ الكويت

\title{
1/1 1/1
}

يعد الإرسال واحده من أهم المهارات الهجومية في الاسكواش التى ينبغي علي اللاعب إجادتها بإتقان حتي تجبر المنافس علي الدفاع وتدفعه إلي الزوايا الخلفيه وتجبره علي أداء ضربات جانبية من الخلف مما يعطيك الفرصة للسيطرة علي منتصف الملعب ما يجعلك دائماً في وضع الهجوم والسيطرة علي منتصف الملعب.

ويذكر علي جهاد (2014م) أن الإرسال هو أحد مهارات رياضة الاسكواش، حيث يستطيع اللاعب إستغلاله فى تحقيق بداية هجومية ناجحة للفوز بالنقاط، ويبدو الإرسال سهل الأداء ولكنه يحتاج إلى ساعات طويلة من التدريب حتى يصل إلى مستوى جيد من الإتقان والدقة، كما يحتاج إلى توافق عضلى عصبى حتى يكون ناجحاً، حيث أن درجة صعوبة الإرسال تمكن اللاعب من إتخاذ الوضع المناسب الذى يسح له بضرب الكرة بعد ردها من المستقبل بأداء متقن، حيث يعتبر الضربة الوحيدة التى يستطيع اللاعب ضرب الكرة أثناء أدائه بإتقان تام، بالإضافة إلى أنها المهارة الوحيدة فى الاسكواش التى يؤديها اللاعب بدون ضغط من المنافس وذلك بسبب بعد اللاعب عن (99 : (1) منطقة التمركز ويتم أداء مهارة الإرسال من مربعي الإرسال الأيمن والأيسر، حيث يكون أداء الإرسال من مربع الأرسال الأيسر بوجه المضرب الأمامي، ويكون أداء الإرسال من مربع الإرسال الأيمن بوجه 
المضرب الخلفي، وفي كلتا النوعين يكون الإرسال عامل حاسم للنجاح والتفوق في المباراه، ولذلك فإن اللاعبين المحترفين يبذلون قصاري جهدهم في تطوير إرسالهم بهدف الضغط علي المنافس وجعله غير متوازن حتي يقوموا بعملية الهجوم. 2/1 مشكلة البحث وأهميته

يعتبر الإرسال من المهارات الهجومية الهامة والتى تحتاج إلي وقت طويل للتدريب وتكمن المشكله هنا إذا ظل اللاعب يتدرب علي الأداء الفني الغير الصـيح ولم تتطرأ معظم مراجـع الاسكواش عن الأداء الفني للإرسـال سـواء بوجـه المضـرب الأمـامي أو وجـه المضـرب الخلفي بالطريقـه الفنيـه المفصـله، ويعـاني اللاعبون في بدايـة التعليم مـن صعوبة الإرسـال بسبب جهل بعض المدربين بالأداء الفني وعدم قدرتهم علي إكتثاف الأخطاء، كما أن الهدف من الإرسال ليس إدخال الكره الملعب فقط ولكن إرسال كره صسبه إلي المنافس لايستطيع ردها وإن قام برد الكره يكون في وضع دفاع وليس الهجوم حتي يتثنى للاعب أخذ النقطه ويحافظ علي الإرسال في حوتته، وهذا لايتم الإ إذا إستطاع اللاعب أن يؤدي المهاره بأداء فنى صحيح وتحكم في سرعة الكرة وكذلك قدرته علي توجيه الكره في أماكن الصعوبـه في الملعب وهذا مادفع الباحث للقيام بهذا البحث.

3/1 أهداف البحث

يهدف هذا البحث إلى التعرف على الفروق البيوميكانيكية للذراع الضاربة لمهارة الإرسال العالي بوجه المضرب الأمامي والخلفي وذلك من خلال: 1/3/1 التعرف علي دلالة الفروق البيوميكانيكية للذراع الضاربة لمهارتي الإرسال العالي بوجه المضرب الأمامي والخلفي خلال لحظتى المرجحه والتصادم. 
2/3/1 التعرف علي دلالة الفروق للزوايا والسرعات الزاويا للذراع الضاربة لمهارتي الإرسال العالي بوجه المضرب الأمامي والخلفي خلال لحظتى المرجحه والتصادم.

3/3/1 التعرف علي دلالة الفروق للمؤشرات البيوميكانيكية للكره لمهارة الإرسال العالي بوجه المضرب الأمامي والخلفي خلال لحظة والتصادم. 4/1 فروض البحث

1/4/1 قد توجد فروق داله إحصائياً بين الإرسال العالي بوجه المضرب الأمامي والخلفي للمؤشرات البيوميكانيكيه المختاره للذراع الضاربه خلال لحظتى المرجحه والتصادم. 2/4/1 قد توجد فروق داله إحصائياً بين الإرسال العالي بوجه المضرب الأمامي والخلفي للزوايا والسرعات الزاويا للذراع الضاربه خلال لحظتى المرجحه والتصادم.

3/4/1 قد توجد فروق داله إحصائياً بين الإرسال العالي بوجه المضرب الأمامي والخلفي للمؤشرات البيوميكانيكية للكره.

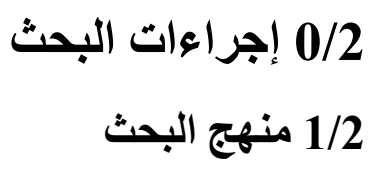

إستخدم الباحث المنهج الوصفى بإستخدام التحليل البيوميكانيكي ثنائي الأبعاد، معتمداً على

أسلوب التصوير بالفيديو عالي السرعة، وبإستخدام برنامج الحليل Simi Motion Analyses.

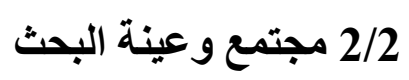

تم إختيار عينة البحث بالطريقة العمدية وإشتملت على (5) لاعبين مصنفين من أفضل ثمانية لاعبين على مستوى دولة الكويت تحت 19 سنة، وقام كل لاعب بأداء (2) محاولات لكل مهاره من المهارات قيد البحث، لتصبح عدد المحاولات التي تم تحليلها والتي خضعت للمعالجات 
الإحصائية 10محاولات للارسال بوجة المضرب الامامي و10 محاولات للارسال بوجه المضرب

جدول (1) جئية

التوصيف الإحصائى للعينة الكلية في متفيرات النمو والعمر التدريبى

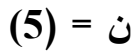

\begin{tabular}{|c|c|c|c|c|c|}
\hline الإلتواء & الوسيط & الإنحراف المعياري & المتوسط الحسابي & وحدة القياس & المتغيرات \\
\hline $1,71-$ & 19 & 0,58 & 18,67 & سنة & السن \\
\hline 0,49 & 173 & 4,04 & 173,67 & سم & إرتقاع القامة \\
\hline 1,18 & 73,50 & 2,87 & 74,63 & كيلو جرام & الوزن \\
\hline 1,71 & 8 & 0,58 & 8,33 & سنة & العمر التدريبي \\
\hline
\end{tabular}

يتضح من الجدول رقم (1) أن جميع قيم معاملات الإلتواء لعينة البحث تراوحت ما بين

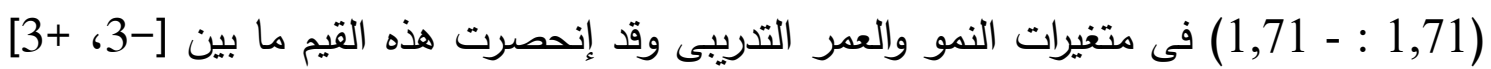
مما يدل على تجانس العينة. 3/2 أدوات وأجهزة جمع البيانات 1/3/2 الأدوات المستخدمة • جهاز رستاميتر Restameter Pe 3000 لقياس إرتقاع القامة لأقرب سم. • ميزان طبى معايير لقياس الوزن Medical Scale for Wight بالكيلو جرام. ملعب إسكواش قانونى + مضرب إسكواش + كرة إسكواش.

2/3/2 أجهزة التحليل الحركي (مرفق 1) • وحدة كمبيوتر متطورة. برنامج التحليل الحركي Simi Motion Analysis.

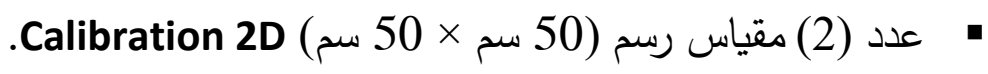
• • عدد (2) كاميرا فيديو عالية السرعة من 50 إلى 250 كادر/ثانية من نوع .Imaging 
عدد (2) كارت ذاكرة سعة (64) جيجا بايت ماركة San Disk.

عدد (2) حامل ثلاثي مزود بميزان ماء.

وصلات كهربائية.

3/3/2 برنامج التحليل الحركي

قام الباحث بالتصوير وإجراء التحليل الحركي للمهارتين قيد البحث، مستخدماً برنامج التحليل

\section{الحركي (Simi Motion Analysis).}

4/3/2 اللحظات قيد البحث

قام الباحث بدراسة التحليل الفني لأداء للمهارتين قيد البحث وذلك للوقوف علي أهم اللحظات أثناء الأداء وقد قام الباحث بتحديد اللحظات الآتية للدراسة : - لحظة المرجحة وهي لحظة بداية حركة رسغ اليد الحاملة للمضرب حتي نهاية لحظة المرجحة وقبل التصادم.

- لحظة التصادم وهي لحظة إلتقاء منتصف تارة المضرب مع الكرة قبل إنطلاقها تجاة

$$
\text { 5/2 الدراسات الاستطلاعية الأمامي }
$$

أجرى الباحث الدراسة الاستطلاعية يوم الجمعة الموافق 2019/12/20م بملعب الاسكواش بهيئة إستاد القاهرة بمدينة نصر أثناء معسكر منتخب الكويت بالقاهرة للإستعداد لبطولة الخليج، وبلغت عينة الدراسة الاستطلاعية (2) لاعبين ومن خارج العينة الأساسية وكان من أهم أهداف هذه الدراسة:

التأكد من صلاحية المكان الذى سيتم فيه التصوير وأيضاً وسائل وأدوات جمع البيانات. 
تحديد مكان وإرتفاع وضع الكاميرات وزاوية التصوير •

تحديد أنسب درجة إضلاءة مطلوبة تصلح للتصوير •

6/2 الاراسة الأسساسية

قام الباحث بإجراء التجربة الأساسية يوم الأربعاء الموافق 2019/12/25م الساعة الثالثة

عصراً وذلك بملعب الإسكواش بهيئة إستاد القاهرة بمدينة نصر أثناء معسكر منتخب الكويت بالقاهرة للإستعداد لبطولة الخليج، حيث تم وضع الكاميرا الأولي عمودية على اللاعب وعلي بُعد 4,50 دتر من اللاعب و4.00 متر من الخط الخلفى للملعب وباءرتفاع 90 سم وبزاوية 90 درجة علي اللاعب، وتم ضبط سرعة الكاميرا علي 125 كادر/ث، ثم قام الباحث بوضع الكاميرا الثانية موازية للحائط الأمامى لملعب الإسكواش وعلى بُعد 5,44 متر من خط مربع الإرسال على خط الـ وبإرتفاع 1,78 متر حيث أن هذا الإرتفاع هو إرتفاع خط الإرسال على الحائط الأمامي. 7/2 المعالجات الاحصائية

بعد إجراء عملية التحليل لعدد (20) محاولات وتجميع النتائج المستخلصة من التحليل الحركى، قام الباحث بإجراء المعالجات الإحصائية المناسبة لتحقيق أهداف البحث والتأكد من صحة الفروض بواسطة برنامج SPSS، حيث إرتضى الباحث مستوى معنوية 0,05 للدلالة وتم حساب مايلى:

- - المتوسط الحسابي Mean، الوسيط Median، الإنحراف المعياري

\section{Deviation}

t-Test: (T) 0/3 عرض ومناقشة النتائج 
1/3 عرض ومناقثة الفرض الأول والذي ينص علي "قد توجد فروق داله إحصائياً بين الإرسال

العالي بوجه المضرب الأمامي والخلفي للمؤشرات البيوميكانيكيه المختاره للذراع الضاربه خلال

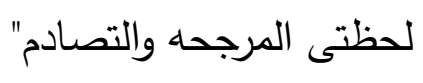

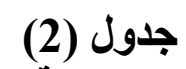

دلالة الفروق للمؤشرات البيوميكانيكية بين الإرسال الخلفي والأمامي خلال لحظة المرجحة

\begin{tabular}{|c|c|c|c|c|c|c|}
\hline \multirow[b]{2}{*}{ المحسوبة (ت) } & \multicolumn{2}{|c|}{ الارسال الامامي } & \multicolumn{2}{|c|}{ الارسال الخلفي } & \multirow[b]{2}{*}{ المؤشر ات البيوميكانيكية } & \multirow[b]{2}{*}{ b } \\
\hline & المعياري & الحستبي & المعياري & الحستوسي & & \\
\hline *5.34 & 0.09 & 0.31 & 0.13 & 0.59 & الازاحة الافقية للكتف الايمن & 1 \\
\hline${ }^{*} 6.78$ & 0.02 & 1.52 & 0.03 & 1.44 & الازاحة الرأسيةة للكتف الايمن & 2 \\
\hline${ }^{*} 5.65$ & 0.41 & 0.71 & 0.17 & -0.08 & السر عة الافقية للكتف الايمن & 3 \\
\hline${ }^{*} 2.47$ & 0.14 & 0.06 & 0.49 & 0.46 & السرعة الرأسية للكتف الايمن & 4 \\
\hline${ }^{*} 5.28$ & 0.08 & 0.14 & 0.18 & 0.48 & الازاحة الأفقية للمرفق الايمن & 5 \\
\hline${ }^{*} 6.35$ & 0.03 & 1.28 & 0.03 & 1.19 & الاز احة الرأسية للمرفق الايمن & 6 \\
\hline 0.53 & 0.54 & 1.82 & 0.88 & 1.65 & السرعة الافقية للمرفق الايمن & 7 \\
\hline${ }^{*} 3.12$ & 0.33 & 0.19 & 0.36 & -0.29 & السرعة الرأسية للمرفق الايمن & 8 \\
\hline${ }^{*} 6.85$ & 0.09 & -0.16 & 0.12 & 0.16 & الازاحة الافقية لرسغ اليد الايمن & 9 \\
\hline${ }^{*} 13.24$ & 0.03 & 1.47 & 0.06 & 1.19 & الازاحة الرأسية لرسغ اليد الايمن & 10 \\
\hline${ }^{*} 2.61$ & 0.56 & 0.63 & 1.22 & 1.74 & السر عة الافقية لرسغ اليد الايمن & 11 \\
\hline 0.70 & 0.38 & -1.41 & 0.73 & -1.59 & السرعة الرأسية لرسغ اليد الايمن & 12 \\
\hline
\end{tabular}

قيمة "ت" الجدولية عند مستوى 0,05 ودرجات حرية 18 = 2,101

أظهرت نتائج جدول رقم (2) أن قيم المتوسطات للإزاحات الأفقية للكتف والمرفق أبعد في

الإرسال العالي بوجه المضرب الخلفي عنه في الإرسال الأمامي، عدا الإزاحه الأفقية لرسغ اليد

الأيمن فكانت للإرسال بوجه المضرب الأمامي أبعد من الإرسال الخلفي ويعذي الباحث ذلك إلي

أنه أثناء لحظة المرجحة تكون الذراع الضاربة في الإرسال الأمامي أبعد خلا لحظة المرجحه

حيث أنها تأتي من خارج الجسم حتي نقطة التصادم، أما في الإرسال الخلفي فتأتي الذراع الضاربه

من أمام الصدر ولأعلي ولذلك رسغ اليد يتحرك لمسافه أكبر عنه في الإرسال الأمامي، وهذا يتفق 
مع جمال الثافعي (2001) أن المرجحه في الإرسال الأمامي تأتي من الجانب الأيمن وخارج الجسم بحيث تكون هناك زاويه قائمه بين زاوية المرفق مع الساعد، والمرجحه في الإرسال الخلفي تأتي من أمام الصدر بحيث تكون زاوية المرفق مع الساعد زاوية حاده وتكون أمام الذقن. كما أظهرت نتائج جدول رقم (2) أن الإزاحة الرأسيه للكتف الأيمن والمرفق الأيمن ورسغ اليد الأيمن للذراع الضاربة كانت قيم المتوسطات للإزاحات الرأسيه للإرسال الأمامي أكبر من الإرسال الخلفي ويعذي الباحث ذلك لأنه في الإرسال الأمامي تكون الذراع الضاربه تأتي من أعلي وزاوية الساعد مع العضد زاوية شبة قائمه خلال لحظة الرجحة، وهذا يساعد علي إتمام عملية Yong-Hwan, النقل الحركي من الجذع إلي الذراعين، ويتق ذلك مع نتائج يونغ هوان وآخرون et al. الإزاحة الرأسية لكتف الذراع الضاربة. كما أظهرت نتائج جدول رقم (2) أن السرعة الأفقية للكتف والمرفق كانت أكبر في الإرسال العالي بوجه المضرب الأمامي أما السرعة الأفقية لرسغ اليد كانت أكبر في الإرسال الخلفي، ويعذي الباحث ذلك كنتيجة منطقية لكبر الإزاحة الأفقية في الإرسال الخلفي عنه في الأمامي وذلك لأن الدسار الحركي للذراع الضاربة أثناء لحظة المرجحة في الإرسال الخلفي تأخذ مسافة مرجحة من أمام الصدر حتي منطقة تصادم المضرب مع الكرة وهذا يتفق مع علي جهاد(2014) أن المرجحه في الإرسال الأمامي أقل قوة ومسافه من المرجحه في الإرسال الخلفي نظراً لصعوبة

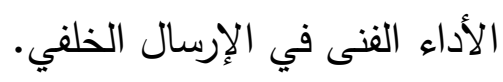
كما أظهرت نتائج جدول رقم (2) أن السرعة الرأسيه للكتف الأيمن والمرفق ورسغ اليد كانت الدتوسطات أكبر في الإرسال الخلفي عنه في الإرسال الأمامي ويعذي الباحث ذلك إلي أن هناك 
حريه للمسار الحركي للمضرب لأنه يأتي من أمام الصدر لحظة المرجحه، لذلك كانت قيم متوسطات السرعات الرأسيه أكبر في الإرسال الخلفي عنه في الإرسال الأمامي وهذا يتفق أيضاً مع السلسله الكينماتيكية المفتوحة، فإن هذه المرجحه تتيح الفرصة الجيدة لإنتاج القوة وذلك لأنها مهارة وحيده والمرحلة التمهيدية بها تكون عكس إتجاه الحركة، كما يعد الإرسال الأمامي والخلفي من المهارات المغلقه التى لايتقيد فيها اللاعب بشروط أو زمن ملزم للأداء، وهذا يتفق مع دراسة يونغ هوان وآخرون .Yong-Hwan, et al"(2007) وأشارت النتائج إلى أن زمن أداء الضربة الخلفية من لحظة المرجحة الخلفية إلى نهاية مرحلة المتابعة 0,39 ثانية والذى يتضمن 0,24 ثانية دن لحظة المرجحة الخلفية إلى لحظة التصادم، و0,15 ثانية.

$$
\text { (3) جدول }
$$

دلالة الفروق للمؤشرات البيوميكانيكية بين الإرسال الخلفي والأمامي

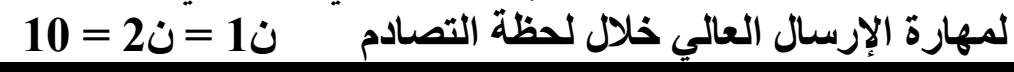

\begin{tabular}{|c|c|c|c|c|c|c|}
\hline \multirow[b]{2}{*}{ قالمحسوبة (ت) } & \multicolumn{2}{|c|}{ الارسال الامامي } & \multicolumn{2}{|c|}{ الارسال الخلفي } & \multirow[b]{2}{*}{ المؤشرات البيوميكانيكية } & \multirow[b]{2}{*}{ p } \\
\hline & المعياري & الحسابي & المعياري & الحسابي & & \\
\hline *4.43 & 0.09 & 0.42 & 0.13 & 0.62 & الازاحة الافقية للكتف الايمن & 1 \\
\hline *9.86 & 0.03 & 1.56 & 0.02 & 1.46 & الازاحة الرأسية للكتف الايمن & 2 \\
\hline 1.92 & 0.17 & 0.25 & 0.15 & 0.11 & السرعة الافقية للكتف الايمن & 3 \\
\hline *2.31 & 0.09 & 0.05 & 0.26 & 0.27 & السرعة الرأسية للكتف الايمن & 4 \\
\hline *7.16 & 0.09 & 0.35 & 0.12 & 0.73 & الازاحة الافقية للمرفق الايمن & 5 \\
\hline${ }^{*} 7.54$ & 0.04 & 1.28 & 0.04 & 1.16 & الازاحة الرأسية للمرفق الايمن & 6 \\
\hline *2.35 & 0.31 & 1.32 & 0.48 & 0.94 & السرعة الافقية للمرفق الايمن & 7 \\
\hline 0.40 & 0.42 & -0.33 & 0.39 & -0.38 & السرعة الر أسية للمرفق الايمن & 8 \\
\hline${ }^{*} 6.44$ & 0.09 & 0.37 & 0.15 & 0.79 & الازاحة الافقية لرسغ اليد الايمن & 9 \\
\hline${ }^{\star} 7.64$ & 0.06 & 1.18 & 0.07 & 0.97 & الازاحة الرأسية لرسغ اليد الايمن & 10 \\
\hline 1.63 & 0.64 & 5.55 & 0.71 & 5.06 & السرعة الافقية لرسغ اليا الايمن & 11 \\
\hline$\star 5.03$ & 0.34 & -1.91 & 0.27 & -1.21 & السرعة الرأسية لرسغ اليد الايمن & 12 \\
\hline
\end{tabular}


أظهرت نتائج جدول رقم (3) أن الإزاحات الأفقية للكتف والمرفق ورسغ اليد الأيمن كانت قيم المتوسطات أكبر خلال لحظة التصادم في الإرسال العالي بوجه المضرب الخلفي عنه في الإرسال الأمامي، ويعذي الباحث ذلك إلي أنه لحظة تصادم الكرة مع المضرب في الإرسال الخلفي يقوم اللاعب بميل الجذع للإمام وذلك لحفظ توازن الجسم وذلك نظراً لطبيعة المرجحة ووضع الذراع أمام الجسم، فتكون نقطة التصادم أمام مشط القدم الأيمن تقريباً وهذا الوضع يعطي اللاعب أفضلية أكبر في عملية الضرب والمتابعة، أما في الإرسال العالي بوحه المضرب الأمامي فتكون الذراع الضاربه بجوار الجسم في وضعها التشريحي المثالي وهذا يتفق مع علي جهاد(2014) في أن الإرسال الخلفي يقوم اللاعب بميل الجذع للأمام وذلك بسبب مرجحة اليد لجهة اليسار بحيث يدخل الكوع والساعد ورسغ اليد داخل جسم اللاعب حتي يعطي مرجحة مثاليه وقوة أثناء تصادم الكرة. كما أظهرت نتائج جدول رقم (3) أن الإزاحة الرأسيه للكتف والمرفق ورسغ اليد الأيمن للذراع الضاربة كانت قيم المتوسطات للإزاحات الرأسيه للإرسال الخلفي أكبر من الإرسال الأمامي ويعذي الباحث ذلك لأنه في الإرسال الخلفي تكون لحظة التصادم بين المضرب والكره أعلي من الجذع لأن الذراع الضاربه تأتي من أمام الصدر والمضرب أعلي من الرأس فيكون هناك صعوبة في عملية المرجحه والمسار الحركي للمضرب مما يتيج إنسيابية أكثر لحركة الذراع والجذع خلال لحظة التصادم وذلك علي عكس الإرسال الأمامي الذي يكون فيه الذراع الضاربه فيها حرية أكبر أثناء لحظة التصادم.

كما أظهرت نتائج جدول رقم (3) أن السرعة الأفقية للكتف والمرفق ورسغ اليد الأيمن كانت أقل في الإرسال العالي بوجه المضرب الخلفي عنه في الإرسال الأمامي، ويعذي الباحث ذلك لأن اللاعب يقوم بعمل فرملة برسغ اليد والمرفق والكتف خلال لحظة تصادم المضرب مع الكرة حتي 
يتثني له توجيه الكره إلي منطقة الإرسال القانونية، أي أنه كلما قلت السرعة في الذراع الضاربة تحسنت عملية التوجية والدقة، أما الإرسال بوجه المضرب الأمامي فالمسار الحركي للذراع الضاربة بداية من الكتف مروراً بالمرفق حتي رسغ اليد يتطلب سرعه عاليه وذلك لأن حركة الذراع تكون بإتجاه منطقة الإرسال القانونيه وداخل محيط الجسم.

كمـا أظهـرت نتـائج جدول رقـم (3) أن السـرعة الرأسـيه للمرفق ورسـخ اليــ الأيمـن كانــ المتوسطات أقل في الإرسال الخلفي عنه في الإرسال الأمامي ويعذي الباحث ذلك إلي الفرمله أو التخميد الذي يقوم به اللاعب خلال لحظة التصادم، الأمر الذي يساعد علي عملية النقل الحركي من الكتف إلي رسغ اليد حيث يقوم اللاعب بتثبيت مفصلي رسن اليد والمرفق حتي يستفيد إستفاده كامله من المرجحه الرجوعيه للذراع الضـاربه وتشبه هذه الحركة مثل حركة السوط (الكرباج)، أمـا عن دلالتة فروق السرعة الرأسيه للكتف الأيمن في الإرسال الخلفي فكانت قيم المتوسطات أعلي عنه في قيم الإرسال الأمامي ويعذي الباحث ذلك إلي ان اللاعب يقوم بعملية ميل الكتف للأمام ولإسفل حتي تعطي حرية أكبر وإتزان أفضل للاعب أثناء لحظة التصادم، وذلك علي العكس من الإرسـال العـالي بوجـه المضـرب الأمـامي حيث يكون وضـع مفصل الكتف في وضـعه التشريحي الطبيعي، وهذ ما يفسرة جمال محمد علاء الدين وناهد أنور الصباغ(1999) بأن النقل الحركي قد يكون من الجذع إلى الأطراف كما فى مسابقات الرمي والارسال وقد يكون من الأطراف إلى الجذع كما فى جميع أشكال الإرتقاء. 2/3 عرض ومناقثة الفرض الثاني والذي ينص علي " قد توجد فروق داله إحصائياً بين الإرسال العالي بوجه المضرب الأمامي والخلفي للزوايا والسرعات الزاويا للذراع الضاربه خلال لحظتى المرجحه والتصادم." 
جدول (4)

دلالة الفروق للمؤشرات البيوميكانيكية للزوايا بين الإرسال الخلفي والأمامي ن 1 =

خلال لحظة المرجحة

\begin{tabular}{|c|c|c|c|c|c|c|}
\hline \multirow[b]{2}{*}{ قالمحسوبة } & \multicolumn{2}{|c|}{ الارسال الامامي } & \multicolumn{2}{|c|}{ الارسال الخلفي } & \multirow[b]{2}{*}{ المؤشرات البيوميكانيكية } & \multirow[b]{2}{*}{ b } \\
\hline & الالتحرَاف & الحسابي & الالتحرَاف & الحستوسط & & \\
\hline *14.25 & 6.87 & 43.23 & 1.46 & 10.92 & زاوية الكتف الأيمن & 1 \\
\hline${ }^{*} 5.74$ & 2.49 & -3.40 & 0.74 & 1.13 & السرعة الزاوية للكتف الايمن & 2 \\
\hline 0.53 & 7.46 & 93.89 & 7.04 & 90.14 & زاوية المرفق الايمن & 3 \\
\hline${ }^{*} 6.59$ & 2.46 & 2.42 & 2.78 & -4.74 & السرعة الزاوية للمرفق الايمن & 4 \\
\hline${ }^{*} 6.50$ & 17.81 & 182.29 & 3.16 & 146.98 & زاوية رسغ اليد اليمنى & 5 \\
\hline 0.04 & 16.32 & -0.83 & 2.79 & -2.20 & السرعة الزاوية لرسغ اليد اليمنى & 6 \\
\hline
\end{tabular}

أظهرت نتائج جدول رقم (4) أن قيم الزوايا للكتف والمرفق ورسغ اليد الأيمن كانت أقل

بمقارناتها بننفس قيم زوايا الإرسال الأمامي، ويعذي الباحث ذلك إلي الوضع التشريحي للذراع الضاربه أثناء لحظة المرجحه، ففي الإرسال الخلفي تأتي المرجحه للذراع الضاربه من أعلي الرأس وأمام الصدر أما في الإرسال الأمامي فتكون الذراع الضاربه بجوار الجسم ولأعلي. أظهرت نتائج جدول رقم (4) أن قيم السرعات الزاويا للكتف الأيمن كانت قيم المتوسطات أقل في الإرسال الخلفي عنه في الإرسال الأمامي وذلك لأن مرجحة الذراع الضـاربه تكون لداخل الجسم ولذلك يكون هناك إعاقه في عملية المرجحه وذلك علي العكس في الإرسال الأمامي فتكون مرجحة الذراع الضاربة بجوار الجسم وخارجه، أما السرعات الزاويا للمرفق ورسغ اليد الأيمن فكانت أكبر بمقارناتها بننفس قيم السرعات الزوايا للإرسال الأمـامي، ويعذي الباحث ذلك أن الوضـع التشريحي لمفصلي المرفق ورسخ اليد في الإرسال الأمامي يكون أصعب لأن الذراع تكون خارج الجسم وذلك علي العكس في الإرسال الخلفي بحيث تكون المرجحه إلي داخل الجسم، وهذا يتفق مـع "إليوت بروش وآخرون Elliott Bruce et, al" (1996) أن نسب مساهمة حركة دوران 
الطرف العلوي من الجسم فى الأداء على التوالى هى 46,1\% لدفصل الكتف، 18,2٪ لمفصل رسخ اليد، 12\% للساعد، كما تثير النتائج إلى أن حركة الكب للساعد والإنقباض الزائد لمفصل الكوع يلعبان دوراً هاماً فى توليد السرعة الكافية للمضرب خلال مرحلة ما قبل التصادم.

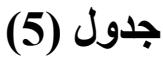
دلالة الفروق للمؤشرات البيوميكانيكية للزوايا بين الإرسال الخلفي والأمامي ن 10 = 10 خلال لحظة التصادم

\begin{tabular}{|c|c|c|c|c|c|c|}
\hline \multirow[b]{2}{*}{ قالمسيمة (تية) } & \multicolumn{2}{|c|}{ الارسال الامامي } & \multicolumn{2}{|c|}{ الارسال الخلفي } & \multirow[b]{2}{*}{ المؤشرات البيوميكانيكية } & \multirow[b]{2}{*}{ م } \\
\hline & اللانحرافي & الحسابي & الالاتحرافي & الكسابي & & \\
\hline 1.71 & 5.25 & 17.71 & 1.52 & 14.09 & زاوية الكتف الأيمن & 1 \\
\hline${ }^{*} 10.43$ & 1.16 & -3.59 & 0.74 & 0.67 & السرعة الزاوية للكتف الايمن & 2 \\
\hline 1.32 & 25.54 & 157.65 & 5.28 & 152.26 & زاوية المرفق الايمن & 3 \\
\hline *11.35 & 9.10 & 30.67 & 1.98 & -0.94 & السرعة الزاوية للمرفقى الايمن & 4 \\
\hline 0.68 & 47.55 & 120.33 & 6.12 & 137.69 & زاوية رسغ اليد الينهى & 5 \\
\hline *4.73 & 27.79 & 45.14 & 1.63 & -0.53 & السرعة الزاوية لرسغ اليد اليمنى & 6 \\
\hline
\end{tabular}

قيمة "ت" الجدولية عند مستوى

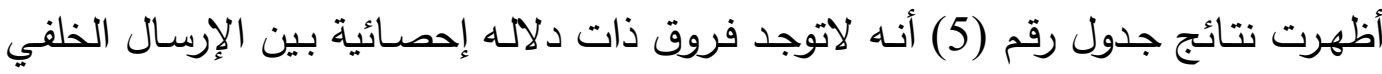

والإرسال الأمامي خلال لحظة التصادم لزوايا الكتف والمرفق ورسغ اليد الأيمن، بينما توجد فروق ذات دلاله إحصائية في السرعات الزاويا لزاوية الكتف والمرفق ورسخ اليد الأيمن لصالح الإرسال الأمامي عن الإرسال الخلفي خـال لحظة التصـادم، ويعذي الباحث ذلك كنتيجة منطقية لحريـة المسـار الحركي للذراع الضـاربة في الإرسـال الأمـامي خـلال لحظـة التصـادم، وهذا يتفق مـع " عارف فاده وآخرون .Ariff Fadiah, et al" (2012) أن إنقباض مفصل الكوع مع حركة الكب من رسغ اليد تلعب دوراً هاماً فى توليد السرعة اللازمة للأداء والمتمثلة فى سرعة تارة المضرب أثناء لحظة التصادم، بالإضـافة إلى أن زوايا مفاصل الجزء العلوي للجسم تؤثر فى أداء مهارتى الضربة الأمامية والخلفية فى الاسكواش، حيث أن السرعات الزاوية والتسارع الزاوي للمفاصل يمثل مؤشر للتعرف على سرعة المقذوف وهو الكرة والناتج عن قوة التصادم مع تارة المضرب. 
3/3 عرض ومناقشة الفرض الثالث والذي ينص علي "التعرف علي دلالة الفروق للمؤشرات البيوميكانيكية للكره لمهارة الإرسال العالي بوجه المضرب الأمامي والخلفي خلال لحظة والتصادم"

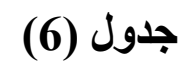

دلالة الفروق للمؤشرات البيوميكانيكية للكرة لمهارة الإرسال العالي بوجه المضرب الأمامي $2 \dot{0}=10$ والخلفي $10=$

\begin{tabular}{|c|c|c|c|c|c|c|}
\hline \multirow[b]{2}{*}{ المحسوبة (ت) } & \multicolumn{2}{|c|}{ الارسسال الامـامي } & \multicolumn{2}{|c|}{ الارسال الخلفي } & \multirow[b]{2}{*}{ المؤشرات البيوميكانيكية } & \multirow[b]{2}{*}{$p$} \\
\hline & المعياري & الحسنابي & المعياري & الحسابي & & \\
\hline *5.92 & 0.12 & 0.40 & 0.12 & 0.70 & Squash ball $X$ & 1 \\
\hline$* 4.28$ & 0.17 & 0.82 & 0.10 & 0.61 & Squash ball Y & 2 \\
\hline *4.21 & 3.13 & 8.44 & 5.25 & 10.93 & Squash ball v(X) & 3 \\
\hline *3.71 & 1.05 & 2.47 & 0.49 & 3.83 & Squash ball v(Y) & 4 \\
\hline
\end{tabular}

أظهرت نتائج جدول رقم (6) أنه توجد فروق ذات دلاله إحصائية للإزاحه الأفقية للكره في

الإرسال الخلفي والأمامي ولصالح الإرسال الخلفي، ويعذي الباحث ذلك إلي أن اللاعب يقوم برمي الكره أمام الجسم في الإرسال الخلفي حتي يتيح له الفرصه في عملية مرجحه أفضل، أما في الإرسال الأمامي فيقوم اللاعب برمي الكره إلي داخل الجسم نظراً لبعد مرجحة الذراع الضاربه لأن المرجحه تأتي من الخلف إلي الأمام، كما يتضح من نفس الجدول وجود فروق ذات دلالة إحصائية للإزاحة الرأسية للكرة في الإرسال الامامي عن الإرسال الخلفي ولصالح الإرسال الأمامي حيث سجلت قيم متوسطات الإزاحة الرأسية للإرسال الأمامي أعلي من قيم متوسطات الإزاحة الرأسيه للإرسال الخلفي ويعذي الباحث ذلك الي أن نقطة التصادم بين المضرب والكره في الإرسال الأمامي تكون أمام منطقة الجذع مباشرة أما في الإرسال الخلفي فتكون أسفل الجذع قليلاً، كما يتضح من نفس الجدول وجود فروق ذات دلاله إحصائية بين الإرسال الخلفي والإرسال الأمامي في السرعات الأفقية والرأسية للكرة حيث سجلت قيم متوسطات السرعات الأفقية والرأسية للإرسال 
الخلفي أعلي من قيم متوسطات السرعات الرأسيه للإرسال الأمامي ويعذي الباحث ذلك الي أن اللاعب يقوم برمي الكره إلي الأمام في إتجاه منطقة الإرسال في الإرسال الخلفي حتي يكتب سرعه اكبر للكره، وهذا يتقق مع يونغ هوان وآخرون .Yong-Hwan, et al" (2007) أن السرعة القصوى للمضرب والكرة تتحدد وفقاً لحركة كل من الكتف، والكوع، ورسغ اليد والتى تعتمد على عملية النقل الحركى من أجزاء الطرف العلوي إلى المضرب ثم الكرة. 0/4 الإستنتاجات والتوصيات 1/4 الإستنتاجات

1/1/4 أن السرعة الأفقية للذراع الضاربة تعتبر مرحلة تمهيدية في إتجاة مغاير للحركة الأساسية. 2/1/4 أن مرحلة بداية مرجحة الذراع الضـاربه في المرحلة التمهيدية لها تأثير كبير علي سرعة

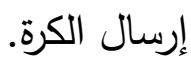

3/1/4 أن لاعب الاسكواش يستفيد من سرعة الكتف الأيمن للذراع الضاربة خلال لحظة التصادم. 4/1/4 أن سرعة الكرة الأفقية والرأسية في الإرسال الخلفي أسرع من الإرسال الأمامي. 2/4 التوصيات : 2/4 1/2/4 الخصائص الميكانيكية التي توصل إليها الباحث يمكن عن طريقها تحديد فاعلية الأداء المهاري للإرسال الخلفي والإرسال الأمامي للاعبي الاسكواش. 2/2/4 يوصي الباحث بوضـع برامج تدريبية خاصـة للإرسـال الخلفي والإرسـال الأمامي للاعبي الاسكواش وفقاً لنتائج البحث. 3/2/4 إستخدام التخصصية الفردية في الترريب وفق متطلبات كل لاعب. 4/2/4 الإهتمام بإعطاء تدريبات لتتمية القوة المميزة بالسرعة للذاعين علي حد السواء. 


\section{奥}

$0 / 5$
المراجع $1 / 5$

1- جمال الثافعى : الإسكواش ( التاريخ - تعليم وتدريب المهارات - قواعد اللعب ) ، دار الفكر

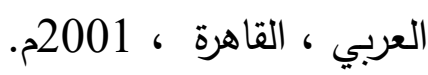

2- جمال محمد علاء الدين وناهد أنور الصباغ: علم الحركة، ط7، دار الكتاب، القاهرة،1999م.

3- علي جهاد رمضان : "الاسكواش (تعليم، تدريب، تدكيم) مطبعة الفرات، بغداد، 2014م.

2/5 المراجع الاجنبية

4- Ariff Fadiah, et al. (2012): Joint angle production during squash forehand and backhand stroke, Paper presented at the 30th international conference on biomechanics in sports, Australia - Melbourne.

5- Elliott, B., Marshall, R., \& Noffal, G. (1996): The role of upper limb segment rotations in the development of rackethead speed in the squash forehand. Journal of sports sciences, 14(2) pp 159-165.

6- Yong-Hwan, et al. (2007): The kinematic analysis of the upper extremity during backhand stroke in squash. Korean journal of sport biomechanics, 17(2) pp 145-156. 